\title{
A Case Study of Downstream Baroclinic Development over the North Pacific Ocean. Part I: Dynamical Impacts
}

\author{
Richard E. Danielson, John R. Gyakum, and David N. Straub \\ Atmospheric and Oceanic Sciences, McGill University, Montreal, Quebec, Canada
}

(Manuscript received 14 March 2005, in final form 31 August 2005)

\begin{abstract}
The impact of eddy energy growth and radiation from a western North Pacific cyclone on the intensity of an eastern North Pacific cyclone a few days later is examined. Associated with the western cyclone is an upstream ridge and trough couplet, initially over Siberia on 8 March 1977. The amplitude of this couplet is perturbed in 5-day numerical simulations of the two marine cyclones. Balanced initial conditions are created by potential vorticity inversion. The magnitude of the upper-level couplet governs much of the subsequent growth of eddy energy in the western cyclone as well as the propagation of eddy energy between the two cyclones. This culminates in measurable changes in the maximum intensity of the eastern surface cyclone. The broader question of the sensitivity of this cyclone to upstream perturbations is also briefly addressed.
\end{abstract}

\section{Introduction}

Midlatitude cyclone development has traditionally been described in terms of a single upper-level trough that overtakes a low-level baroclinic zone (Petterssen and Smebye 1971). Orlanski and Sheldon (1995) reconciled this paradigm with the dependence that some troughs have on an upstream trough or ridge for their movement and intensification. Surveys of the midlatitude upper-level flow (Lee and Held 1993; Chang 1993; Chang and Yu 1999) have suggested that this dynamical dependence, known as downstream development, is significant in trough and ridge life cycles. Anticyclones and cyclones that also exhibit such a dependence have increasingly been identified (e.g., Orlanski and Sheldon 1993; Danielson et al. 2004), though the extent to which such events can be attributed to downstream development remains to be addressed.

The traditional description of cyclone development was given by Hoskins et al. (1985) in terms of a wave train of disturbances on an upper-level potential vorticity (PV) gradient. Associated with each PV anomaly is an induced circulation near the surface. Where a cyclonic anomaly (a trough) overlies a low-level baro-

Corresponding author address: Rick Danielson, Department of Oceanography, Dalhousie University, 1355 Oxford Street, Halifax NS B3H 4J1, Canada.

E-mail: rick@phys.ocean.dal.ca clinic zone, the low-level perturbations can in turn induce a secondary circulation that penetrates upward and amplifies the trough. Perturbations at both levels then develop simultaneously. In addition to the primary dependence on lower- and upper-level baroclinicity, static stability also plays a role. A reduction in stability enhances the vertical penetration depth of the induced circulations and hence the coupling of these perturbations.

Precipitation and latent heat release accompany cyclogenesis and represent an important mechanism for reducing static stability and enhancing development. Diabatic heating within an air mass is equivalent to a redistribution of $\mathrm{PV}$ on the interior of this air mass (Cammas et al. 1994; Hoskins et al. 1985). This was illustrated by the pioneering PV diagnosis of Davis and Emanuel (1991, hereafter DE91), who attributed to precipitation a cyclonic enhancement below the latent heating level. Similarly, Cammas et al. (1994) examined the upper-level jet streak of the "Storm of the 20th Century." They found a diabatic PV flux that is primarily downward, and also a flux on the anticyclonic shear side of the jet streak that appeared to steepen the tropopause. Simulations of a strong coastal cyclone by Davis et al. (1996) further illustrated that diabatic generation of negative PV at upper levels strengthens the local PV gradient and a short-wave ridge immediately downstream. Notably, Davis et al. found such features to be absent in simulations without latent heating (see 
also Wolf and Johnson 1995a,b). The preceding studies broadly confirm the strong dependence of cyclones on the penetration depth of induced circulations, vertical coupling, and local environmental factors that affect these processes. Downstream development is also partially revealed by the impact of moist cyclogenesis on adjacent anticyclonic PV anomalies.

Modeling studies that first described upstream and downstream development within a growing wave train of PV anomalies include Simmons and Hoskins (1979) and Orlanski and Chang (1993). These employed linear and nonlinear simulations of an initially localized perturbation in zonal baroclinic flows. Focusing on the leading edge of the expanding perturbation flow, Simmons and Hoskins found a cessation of upper-level growth prior to that at the surface. This suggested that energy disperses from predecessor upper-level eddies. They also confirmed that the downstream spread of new disturbances occurs at nearly the speed of the upper-level flow.

Similar experiments were diagnosed by Orlanski and Chang (1993) using local eddy energy budgets. They quantified the energy propagation noted above in terms of an ageostrophic geopotential flux between adjacent energy centers, and confirmed that its convergence is a leading term in the initial growth of the downstream energy centers and defines the extent of their subsequent decay as well. In these idealized experiments, the symmetry in disturbances developing from the top downward (on the downstream side of a wave train) and from the surface upward (on the upstream side) was found to be inconsistent with an earlier case study by Orlanski and Katzfey (1991). The latter study revealed mainly downstream energy propagation at upper levels. Orlanski and Chang demonstrated, however, that surface friction reduces the upstream-developing perturbations near the surface. The steering level of a wave train is also lowered and the downstream ageostrophic flow is emphasized in their simulations with a planetary vorticity gradient.

Orlanski and Sheldon (1995) proposed downstream baroclinic development as an extension and clarification of the traditional cyclone development paradigm, and thus emphasized the role of energy propagation between adjacent troughs and ridges. The relevance of this description appears to be both regionally and seasonally dependent. For example, Lee and Held (1993) found that during the Southern Hemisphere summer, the absence of stationary waves and the weak instability of a zonally confined jet stream promote the organization of troughs and ridges into coherent groups called wave packets. Moreover, Chang and Orlanski (1993) used a storm-track model to demonstrate that even if baroclinicity is spatially localized (as it tends to be in the Northern Hemisphere), this does not completely constrain the region of synoptic wave growth. Troughs and ridges that grow where baroclinicity is large also disperse eddy energy and thereby facilitate the growth of waves downstream.

The relevance of downstream baroclinic development to a group of strong cold season cyclones in the eastern North Pacific was examined by Danielson et al. (2004, hereafter DGS). Diagnoses presented there suggest that downstream baroclinic development is a good description of about half of these events. For the bulk of this subset, the propagation of eddy energy could be traced to warm ascent in a western North Pacific cyclone. Hence, some of these eastern cyclones may have developed more intensely owing to precursor cyclones upstream. One good example of this is examined here. Our purpose is to determine whether growth and radiation of eddy energy from the western cyclone affects the development of the eastern cyclone. Following Keyser and Uccellini (1987), we employ numerical simulations whose initial conditions are perturbed upstream. This same event is examined by Danielson et al. (2006, hereafter Part II) in a comparison of eddy energy and wave activity diagnoses.

A description of the model and verification of our control simulation is given in Section 3. Section 4 details how initial conditions are perturbed. The numerical simulations are shown in section 5 , where we focus on downstream energetics and on the intensification of the eastern cyclone. The question of this cyclone's sensitivity is addressed in section 6, followed by a summary in section 7. The next section provides an overview of this event based on gridded analyses and surface observations.

\section{Overview}

Three candidate evolutions were initially chosen from among a group of downstream baroclinic developments (DGS). These were simulated using various physical parameterizations, a large domain, and a relatively coarse grid resolution. The evolution of 8-13 March 1977 was selected for further study based on good comparisons with the National Centers for Environmental Prediction (NCEP) reanalysis (Kalnay et al. 1996) and available surface observations. We begin by characterizing the two North Pacific cyclones involved using the reanalysis and observations (Fig. 1). The origin of the western and eastern troughs can both be traced to positions upstream over Siberia, and the origin of the western surface cyclone is distinct, having formed over southern China (not shown). Our period 
a) 00 UTC 8 March

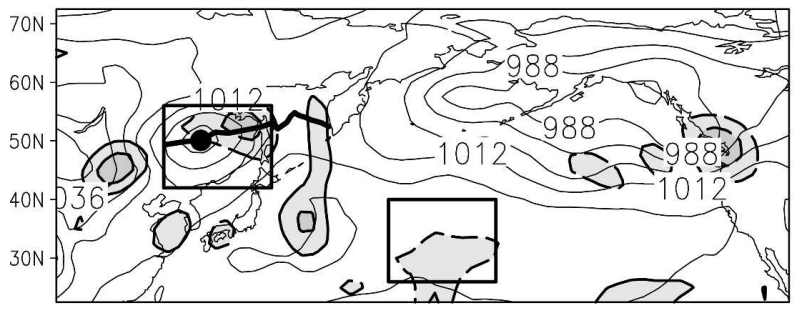

b) 00 UTC 9 March

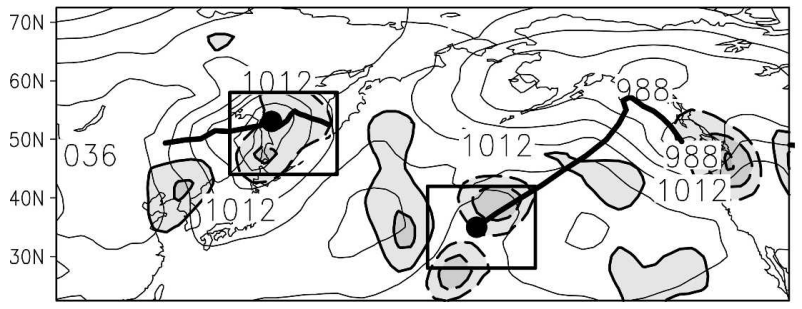

c) 00 UTC 10 March

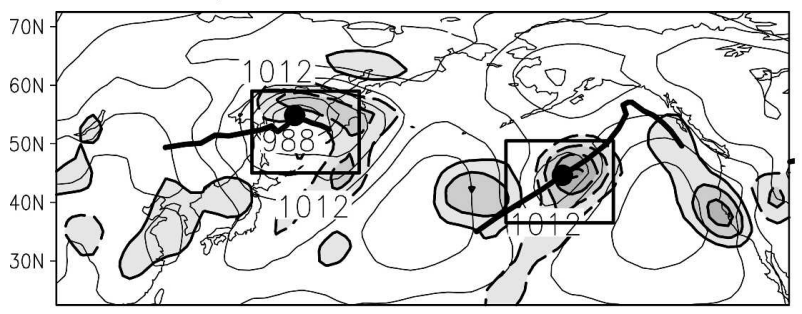

d) 00 UTC 11 March

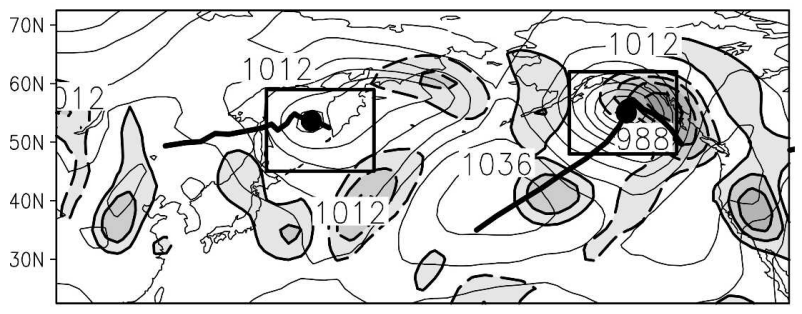

e) 00 UTC 12 March

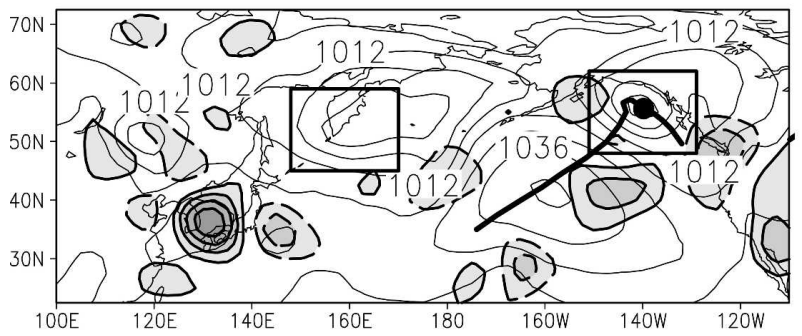

f) Western Storm

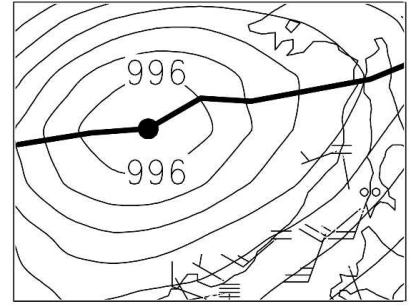

g)

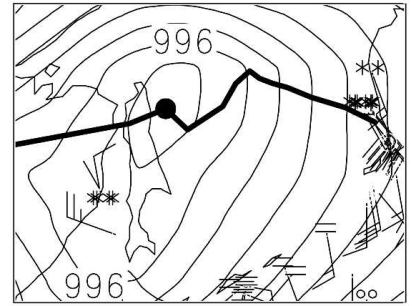

h)

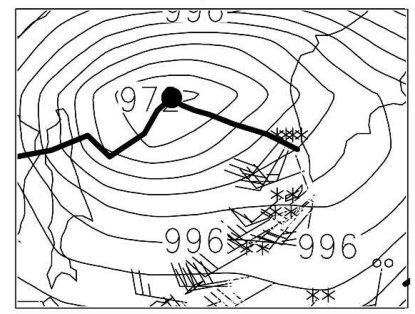

i)

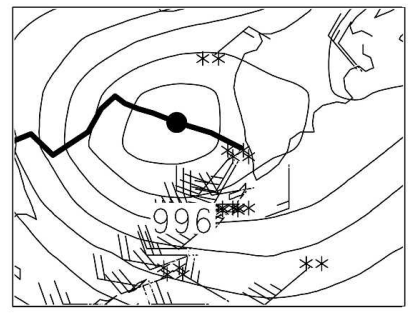

j)

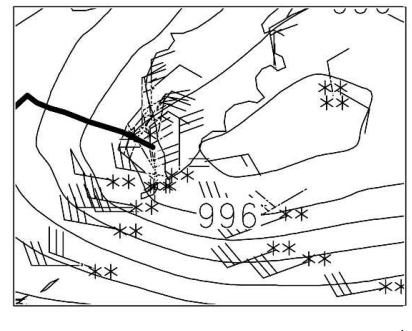

k) Eastern Storm

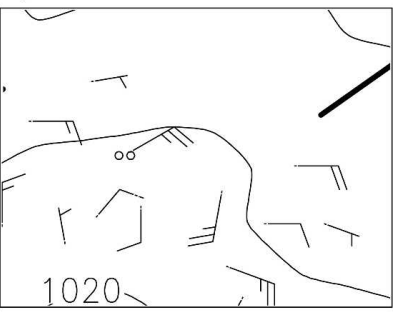

।)

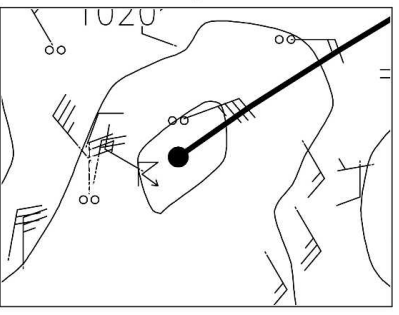

m)

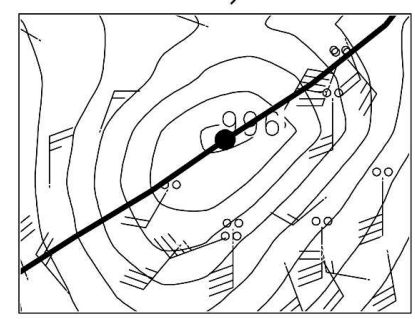

n)

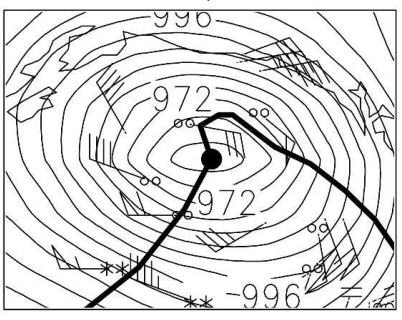

०)

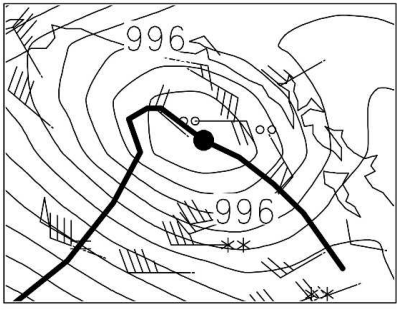

FIG. 1. Sea level pressure evolution for 0000 UTC 8-12 Mar 1977: (a)-(e) Full domains include 500-hPa vertical velocity (shaded; upward motion is dashed) and subdomains (open boxes) that follow the western and eastern surface cyclones. (f)-(o) Subdomains include wind and weather observations taken from ICOADS (see text). Contour intervals are $8 \mathrm{hPa}(4 \mathrm{hPa}$ in the subdomains) for sea level pressure and $0.2 \mathrm{~Pa} \mathrm{~s}^{-1}$ for vertical velocity. Thick lines are the tracks of the western and eastern surface cyclones. Observations of fog, rain, and snow are denoted by bars, dots, and asterisks, respectively. The thunderstorm on 9 Mar (conventional symbol in 1) was observed with heavy rain. Half wind barbs are $2.5 \mathrm{~m} \mathrm{~s}^{-1}$, and full barbs are $5 \mathrm{~m} \mathrm{~s}^{-1}$. 
of interest begins on $8 \mathrm{March}$ as the western trough and surface cyclone converge near the east coast of Asia and their interaction commences. A preexisting eastern trough is found over the central North Pacific Ocean at this time (see section 3 ) and is subsequently associated with the formation and development of the eastern cyclone.

Observations by ships of opportunity and buoys depicted in Figs. 1f-o are obtained from the International Comprehensive Ocean-Atmosphere Data Set (ICOADS; Woodruff et al. 1998). Foggy conditions were reported along the western North Pacific coast on the mornings of 8 and 9 March, as the western cyclone began to move offshore (Figs. 1f,g). Snow then began to fall as this cyclone approached the Kamchatka peninsula (Figs. $1 \mathrm{~g}, \mathrm{~h})$. Maximum winds on the southeast flank of this cyclone were about $20 \mathrm{~m} \mathrm{~s}^{-1}$. There were a few reports of ships accumulating ice on deck and visibility was poor (not shown), but offshore precipitation seems to have been essentially stratiform with little convection observed.

Heavy rain and thunder were reported when the eastern North Pacific cyclone formed near the date line (Fig. 11). As this storm tracked toward the Gulf of Alaska, its greatest intensity occurred at about 0000 UTC 11 March (Fig. 1n), when winds of more than 20 $\mathrm{m} \mathrm{s}^{-1}$ were observed across most of the Gulf of Alaska, the lowest central pressure was $956 \mathrm{hPa}$ according to NCEP manual analyses (Corfidi and Comba 1989), visibility was less than $2 \mathrm{~km}$ to the southeast of the cyclone, and a couple of reports included wave and swell heights of $10 \mathrm{~m}$ (not shown).

\section{Model description and control verification}

Five-day simulations of the western and eastern cyclones are performed from 8 March 1977 using the fifthgeneration Pennsylvania State University-National Center for Atmospheric Research (PSU-NCAR) Mesoscale Model (MM5, version 3; Grell et al. 1994). The duration of each simulation covers a period from two days before, to three days after, the mid point of maximum surface deepening of the eastern cyclone $(0000$ UTC 10 March). The initial period suffices to allow the effect of modifications over Siberia to propagate downstream, and the final period captures both the maximum intensity as well as much of the decay of the eastern cyclone.

The model domain is centered over the western North Pacific Ocean (Fig. 2) and is defined on a polar stereographic grid of $220 \times 160$ points at $90-\mathrm{km}$ resolution (true at $60^{\circ} \mathrm{N}$ ). The model time step is $2 \mathrm{~min}$ and there are 26 vertical levels $[\sigma=1.0,0.99,0.98,0.96$,

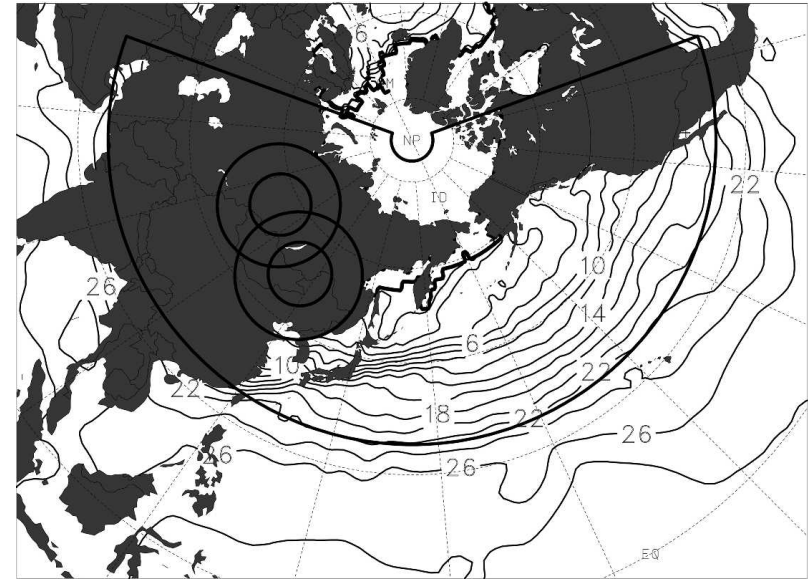

FIG. 2. Model integration domain (full figure), with the subdomain over which balanced initial conditions are substituted (semicircular region), and the subdomains within which potential vorticity is modified (pairs of concentric circles; see text). Also shown are ice cover (polar region bounded by a dark contour) and sea surface temperature (thin contours at $2^{\circ} \mathrm{C}$ intervals). Latitudes and longitudes are shown at $20^{\circ}$ intervals.

$0.93,0.89,0.85,0.8,0.75,0.7,0.65,0.6,0.55,0.5,0.45,0.4$, $0.36,0.32,0.28,0.24,0.2,0.16,0.12,0.08,0.04,0.0$, with the vertical coordinate $\sigma=\left(p-p_{t}\right) /\left(p_{s}-p_{t}\right)$, where $p$ is pressure, $p_{t}$ defines the model top at $30 \mathrm{hPa}$, and $p_{s}$ is surface pressure].

Our treatment of physical processes follows the simulation of another strong eastern North Pacific cyclone by Kuo and Reed (1988). Explicitly resolved precipitation processes are modeled using the scheme based on Hsie and Anthes (1984) that considers distributions of cloud and rainwater and their frozen equivalents. Implicit processes employ the moist convective scheme based on Kuo (1974) that assumes prescribed vertical profiles of convective heating and moistening based on the study by Kuo and Anthes (1984). This parameterization treats convection as a function of the resolvedscale moisture convergence within a column, and has been used extensively at grid resolutions of about 100 $\mathrm{km}$.

All simulations share the same lateral boundary conditions, defined by the 6-hourly NCEP reanalysis, and the same slowly evolving surface fields (e.g., soil temperature and moisture, ice cover, and snow depth). Because a local (in time) sea surface temperature (SST) analysis was unavailable, this field (Fig. 2) is computed from observations taken over 7 days (Danielson 2003). The magnitudes of the corresponding SST anomalies relative to a long-term climatology are less than $2^{\circ} \mathrm{C}$ across most of the North Pacific Ocean (and an alternate estimate of this SST field did not produce large differences in the control simulation; not shown). 

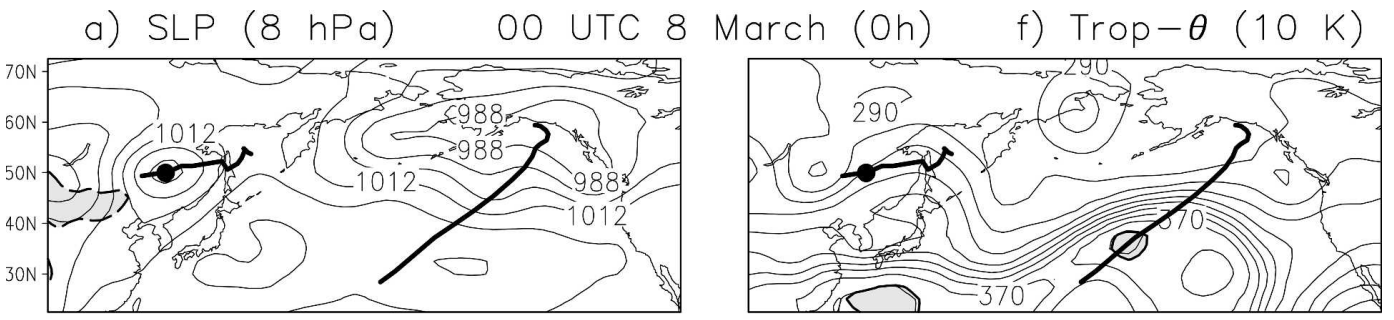

b)

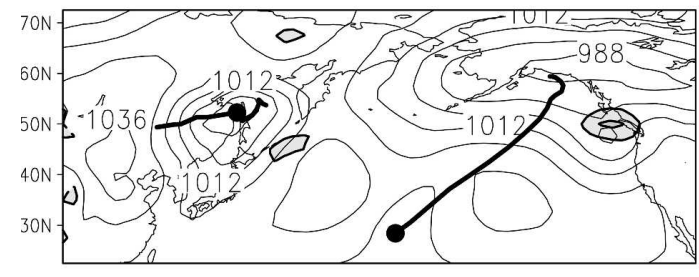

c)

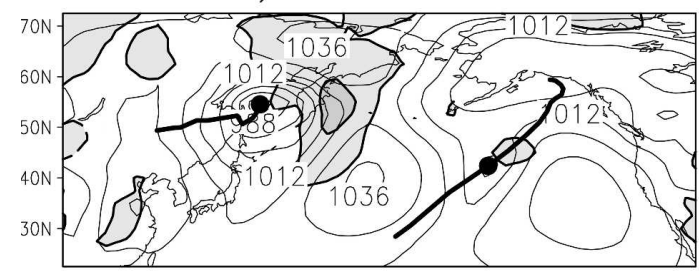

d)

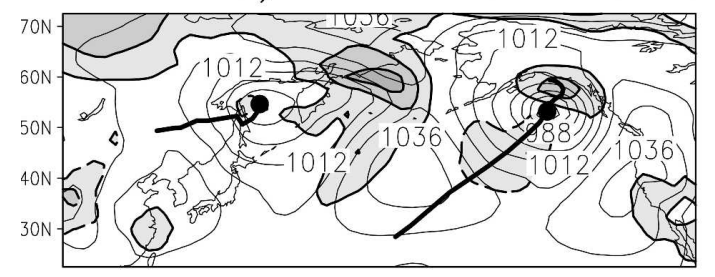

e)

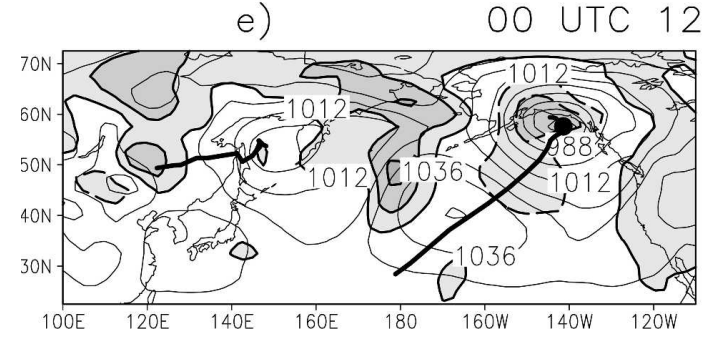

g)

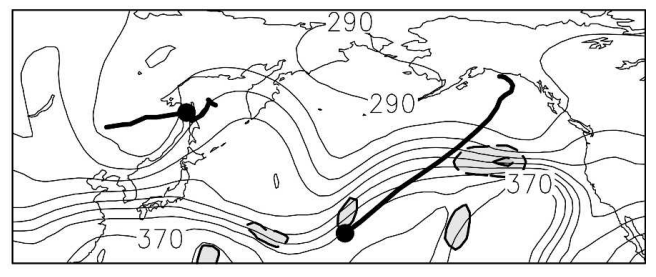

h)

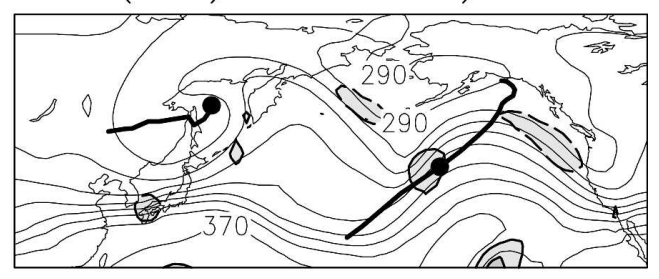

i)
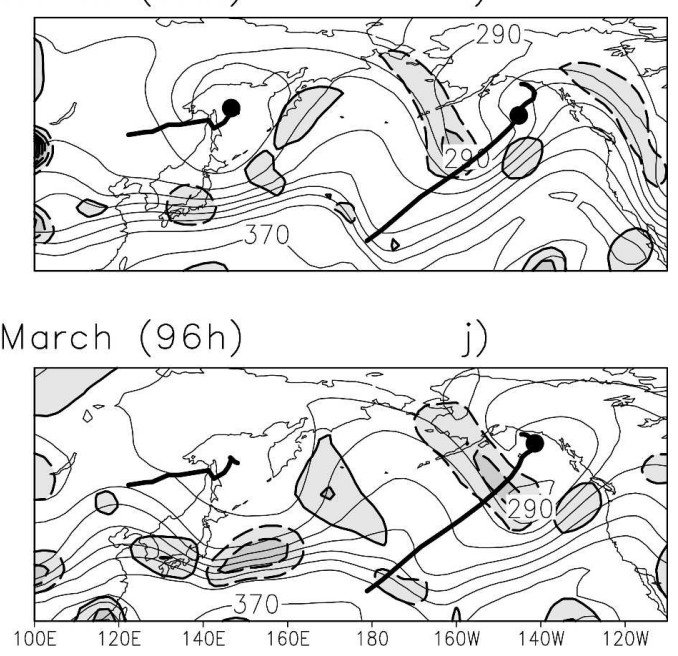

FIG. 3. Comparison of NCEP reanalysis and simulated (a)-(e) sea level pressure and (f)-(j) tropopause potential temperature for 0000 UTC 8-12 Mar 1977. The control simulation is contoured and the difference (control simulation minus NCEP reanalysis) is shaded. Contour intervals for both full fields and difference fields are $8 \mathrm{hPa}$ for sea level pressure and $10 \mathrm{~K}$ for potential temperature. Tracks of the simulated western and eastern surface cyclones are included (thick lines). Here and in subsequent figures the negative contours are dashed.

An assessment of the quality of the control simulation is made in this section with reference to the NCEP reanalysis (analyses hereafter). This seems justified by the good agreement of the surface analyses and ICOADS observations, but we note that the analyses may be poorly constrained by sparse upper-level observations over the ocean. Comparisons of sea level pressure (SLP) and tropopause potential temperature are depicted in Fig. 3 (the shaded fields are control minus the analyses). The western cyclone in the control simu- 
lation is evidently not as intense as in the analyses. Additionally, it stalls upstream of the Kamchatka peninsula, instead of reforming to the east. This results in a large SLP difference near the date line (Figs. 3d,e). The movement of the eastern cyclone in the control simulation lags that of the analyses slightly (Figs. 3c,d), although it depicts a similar intensification and track toward the Gulf of Alaska. Differences in the decay of this case are most noticeable over land, where the simulation depicts a stronger SLP gradient than in the analyses (Fig. 3e).

The dynamic tropopause is taken as the 2-PVU surface (PVU, or PV unit, is defined as $10^{-6} \mathrm{~m}^{2} \mathrm{~s}^{-1} \mathrm{~K}$ $\mathrm{kg}^{-1}$ ). The western and eastern troughs (relatively low potential temperature in Figs. $3 \mathrm{f}-\mathrm{j}$ ) are equatorward and surfaceward extrusions of the dynamic tropopause. An amplification and cyclonic overturning of both the western and eastern troughs is apparent in the simulated evolution. As with the simulated western cyclone, the western trough is located too far upstream on 12 March (Fig. 3j). The overall growth of the western cyclone is well captured by our control simulation, but its decay is somewhat less satisfactory. Apart from a slight time lag and weaker decay, the evolution of the eastern cyclone also appears reasonable.

A summary of error growth in the simulated horizontal geopotential height gradient (a proxy for errors in the geostrophic wind) is gauged by the S1 score (Teweles and Wobus 1954). (Control simulation errors are defined here relative to the analyses, and these are computed using both zonal and meridional differences over the semicircular domain of Fig. 2.) A typical S1 score for a short-term forecast ranges between 20 and 40 and tends to decrease with height (Gyakum et al. 1996). For the initial period of 8-11 March, this score remains between 20 and 30, which indicates that this event may have been unusually predictable. The best S1 score for the latter period is obtained when we compare the analyses and the control simulation, having advanced the control by $6 \mathrm{~h}$ (not shown). This seems to be related to a delay in the spinup of the model (at least in the eastern North Pacific). We return to the spinup and predictability of this event in subsequent sections. The control simulation thus provides an adequate basis for examining dynamical impacts, especially during the first 3 days or so.

\section{Initial conditions}

The major cause of continued intensification by the western cyclone after 0000 UTC 8 March is likely its interaction with the western trough over Siberia (Fig. 3f). This interaction appears to be an important precur- sor of downstream baroclinic development toward the eastern cyclone (DGS; Part II). We thus propose to test the dynamical impact of downstream development on the eastern cyclone by modifying the western trough. It is also useful to modify a prominent ridge farther upstream, as we indicate below.

To maintain a balance between the perturbed mass and wind fields, it is convenient to modify only the PV of the upstream ridge and trough couplet. We then perform PV inversion to obtain the balanced fields that are required as initial conditions (Huo et al. 1999; McTaggart-Cowan et al. 2001). The inversion method used here is that of DE91 and Davis et al. (1996). The appendix provides details of the numerical scheme used to calculate PV initially, as the resulting initial conditions are sensitive to this.

Static inversions of PV are performed over the interior of the model domain and poleward of $25^{\circ} \mathrm{N}$ (the semicircular region shown in Fig. 2). This subdomain encompasses as much of the model domain as possible, but because the balance equation used here is based on a midlatitude scaling, it does not necessarily apply in the Tropics (Daley 1991, section 7). Experiments to place the southern boundary of this subdomain farther south result in larger differences between balanced and analyzed fields at midlatitudes. The downstream baroclinic development of interest occurs entirely within the present subdomain, however. For all simulations, including the control run discussed in section 3 , balanced initial conditions are substituted into this subdomain. No smoothing of the mass or wind fields is applied at the boundaries.

Preliminary model simulations confirmed that the removal of the western trough inhibits the development of the western cyclone, but the presence of a prominent ridge upstream appears conducive for the redevelopment of this trough. A more effective modification is thus to remove both the trough and its upstream ridge. A pair of concentric circles is employed to identify both the negative eddy PV center associated with the ridge and the positive center associated with the trough. Eddy PV of a given sign within an inner domain (to a radius of $750 \mathrm{~km}$ ) is isolated, with a linear decay to the outer domain (at a radius of $1500 \mathrm{~km}$ ), where all other parts of the eddy PV are ignored. We include the eddy $\mathrm{PV}$ from 700 to $150 \mathrm{hPa}$, and the upper-boundary eddy potential temperature between 150 and $100 \mathrm{hPa}$ (Fig. 4). This eddy PV is then removed from the total PV, and the inversion is performed. An eddy is defined relative to a 30-day time mean, following the definition used in Part II. Note that modifications to the PV field are well contained by the inversion domain and are also localized in the western part of the model domain. 
a) $125-\mathrm{hPa} \Delta \theta(2 \mathrm{~K})$

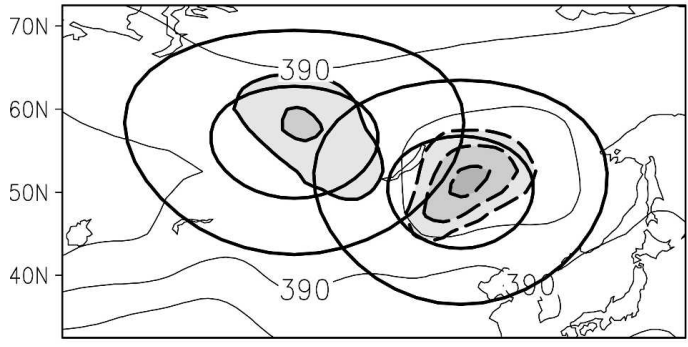

c) $400-\mathrm{hPa} \Delta \mathrm{PV}(1 \mathrm{PVU})$

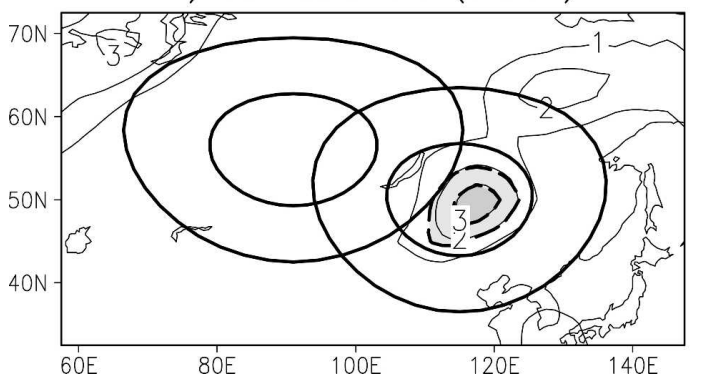

b) $200-\mathrm{hPa} \Delta \mathrm{PV}(1 \mathrm{PVU})$

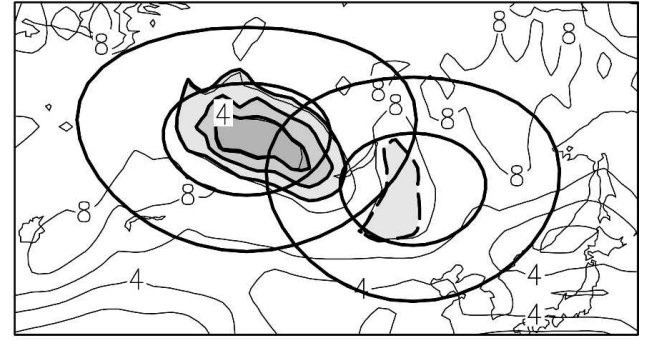

d) $600-\mathrm{hPa} \Delta \mathrm{PV}(0.2 \mathrm{PVU})$

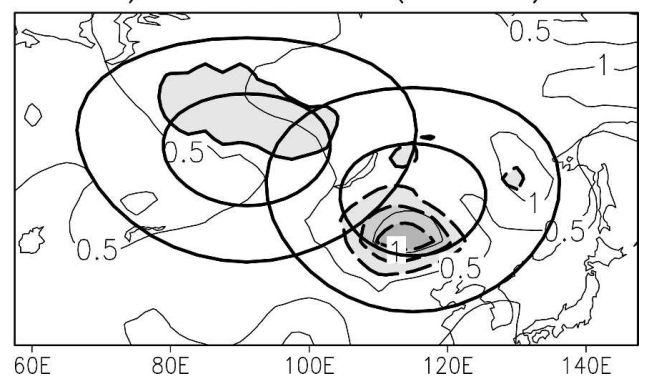

FIG. 4. Modifications of upper-level potential temperature and potential vorticity used to fully remove the western trough and ridge at 0000 UTC 8 Mar 1977. Modifications are shaded and unlabeled, with negative contours dashed, and include the (a) upper-boundary potential temperature (at 2-K intervals) and the (b) 200-, (c) 400-, and (d) 600-hPa potential vorticity (at 1-, 1-, and 0.2-PVU intervals, respectively). Also shown are the corresponding unmodified fields at (a) $10^{\circ} \mathrm{C}$, (b) 2-, (c) 1-, and (d) 0.5-PVU intervals (thin contours). The two pairs of concentric ovals are taken from Fig. 2.

Four simulations are performed. For the control (or no removal) simulation, eddy $\mathrm{PV}$ in the initial conditions is unaltered. A full removal simulation is employed for which the eddy PV of the western trough and ridge are fully removed from the initial conditions. Similarly, half the amplitude of the eddy PV is removed for a half removal simulation, and the eddy PV is augmented by half for a half addition simulation.

Balanced initial conditions at $400 \mathrm{hPa}$ for all four simulations are shown in Fig. 5. The unmodified balanced height field is quite similar to the original analysis (Fig. 5c). The well-developed continental trough and upstream ridge are present to varying degrees, but essentially the entire North Pacific region, including the eastern trough that is found over the central North Pacific, is initially the same in all four simulations. Height differences at other levels are similar both in shape and size. Maximum differences in other variables (not shown) such as the temperature, horizontal winds, and sea level pressure are about $5 \mathrm{~K}, 30 \mathrm{~m} \mathrm{~s}^{-1}$, and $25 \mathrm{hPa}$, respectively.

Before integrating the model, the column-mean horizontal divergence is removed from the initial conditions. The spinup of the model is probably delayed by omitting the divergence component (cf. Davis et al. 1996), but this seems to evolve quickly with minimal impact on the remaining 5-day evolution. (If model errors can be neglected, then an indication that the delay in model spinup for this case is between 6 and $12 \mathrm{~h}$ is shown in Fig. 9.)

\section{Results}

The impact of variations in the intensity of the Siberian ridge and trough couplet are examined in this section. For brevity, we focus on the initial growth of eddy kinetic energy in the western cyclone, followed by downstream development across the North Pacific Ocean (see Part II for a diagnosis using the full eddy kinetic energy budget). This sequence of events can be diagnosed, following Orlanski and Sheldon (1995), in terms of eddy kinetic energy per unit mass $K_{e}=0.5 u^{2}$ $+0.5 v^{2}$ and contributions to its generation, according to

$$
-\boldsymbol{v} \cdot \nabla_{p} \phi=-\alpha \omega-\nabla_{p} \cdot(\phi \boldsymbol{v})_{a}-\frac{\partial}{\partial p}(\phi \omega)
$$

Here, $\nabla_{p}$ is the horizontal gradient operator and the eddy quantities $\boldsymbol{v}, \phi, \alpha$, and $\omega$ are the horizontal wind, geopotential, specific volume, and vertical velocity, respectively. The lhs term is the generation of eddy kinetic energy and represents work done by the pressure 

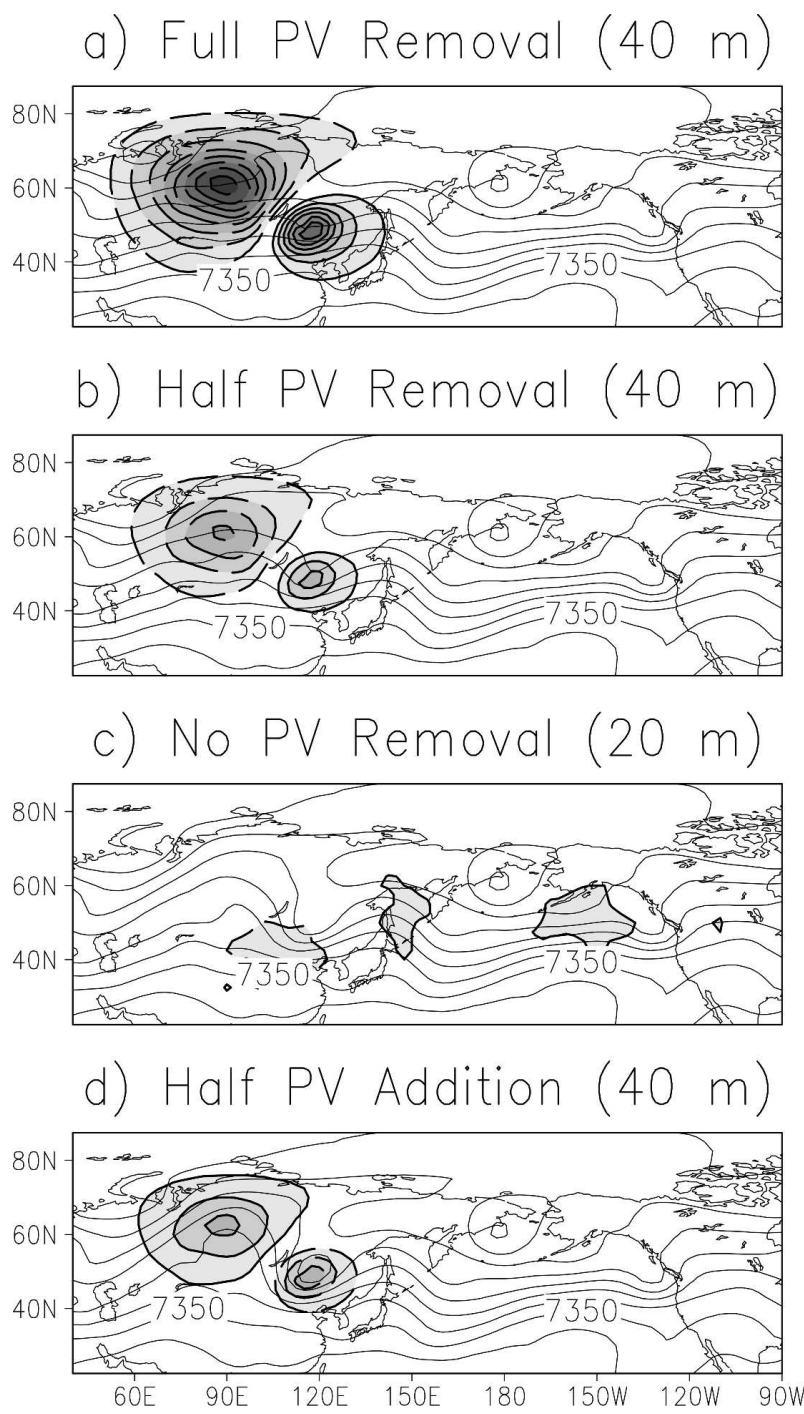

FIG. 5. Balanced initial conditions at 0000 UTC 8 Mar 1977. Geopotential height at $400 \mathrm{hPa}$ based on the (a) full removal, (b) half removal, (c) no removal (control), and (d) half addition of eddy structures shown in Fig. 4. Height differences (shaded) are relative to the balanced height in (c), and differences in (c) are relative to the NCEP reanalysis. Contour intervals are $150 \mathrm{~m}$ for the full fields and (a), (b), (d) 40 and (c) $20 \mathrm{~m}$ for the differences. The domain shown is the semicircular potential vorticity inversion domain of Fig. 2.

gradient in cross-isobaric flow. The first term on the rhs is baroclinic conversion and represents a conversion from eddy available potential to kinetic energy. The last two terms on the rhs define the geopotential flux convergence of eddy energy, and the horizontal component involves the ageostrophic geopotential flux, $(\phi \boldsymbol{v})_{a}$, which is useful for identifying downstream development (Orlanski and Katzfey 1991; Orlanski and Chang 1993). It is defined by Orlanski and Sheldon (1993) as

$$
(\phi \boldsymbol{v})_{a}=\phi \boldsymbol{v}-\hat{\mathbf{k}} \times \nabla \frac{\phi^{2}}{2 f}
$$

where $\hat{\mathbf{k}}$ is a unit vertical vector. This is the eddy geopotential flux with a nondivergent (essentially geostrophic) part omitted. Following Orlanski and Sheldon (1995), when considering column integrals of (1) (i.e., from the surface to $100 \mathrm{hPa}$, normalized by the constant of gravity), the contribution of the vertical geopotential flux convergence term $-\partial(\phi \omega) / \partial p$ can generally be neglected.

As expected from the traditional development paradigm (Petterssen and Smebye 1971; Hoskins et al. 1985), both baroclinic conversion within the western cyclone and the surface cyclone itself correspond well with the amplitude of the trough and ridge couplet immediately upstream (Fig. 6). Baroclinic conversion just ahead of the western cyclone at 1200 UTC 8 March is defined by ascent of relatively warm air, as inferred from Figs. 1a,b. This contribution to the local growth of eddy kinetic energy increases both in extent and intensity with the amplitude of the upstream wave. Collocated with baroclinic conversion in each simulation is a negative contribution defined by ageostrophic geopotential flux divergence. This can be inferred by the energy flux toward the downstream anticyclone. Notably, the magnitude of this flux, and hence the first stage of downstream baroclinic development toward the eastern cyclone (Orlanski and Sheldon 1995), also varies with the amplitude of the upstream wave.

The evolution of eddy kinetic energy in the full removal simulation is shown in Figs. $7 \mathrm{a}-\mathrm{c}$. Note that the energy center near the western cyclone fails to develop. Farther downstream, energy centers that bracket the eastern trough can be found, but they and the geopotential fluxes between them appear strongly damped. Indeed, the two centers seem to be advected downstream with little change in their intensity and a fairly zonal flow being found in their wake. By contrast, the control simulation (Figs. 7e-g) reveals the sequential downstream growth and decay of adjacent eddy kinetic energy centers that is characteristic of downstream baroclinic development. The strongest ageostrophic geopotential fluxes are initially from the energy center near the western cyclone to another immediately downstream, and are subsequently found from this intermediate energy center to the one near the eastern cyclone.

Also shown in Fig. 7 are the half removal and half addition simulations at 1200 UTC 11 March. The energy centers bracketing the eastern trough in the half removal simulation (Fig. 7d) are intermediate in intensity between those of the full removal and the control 

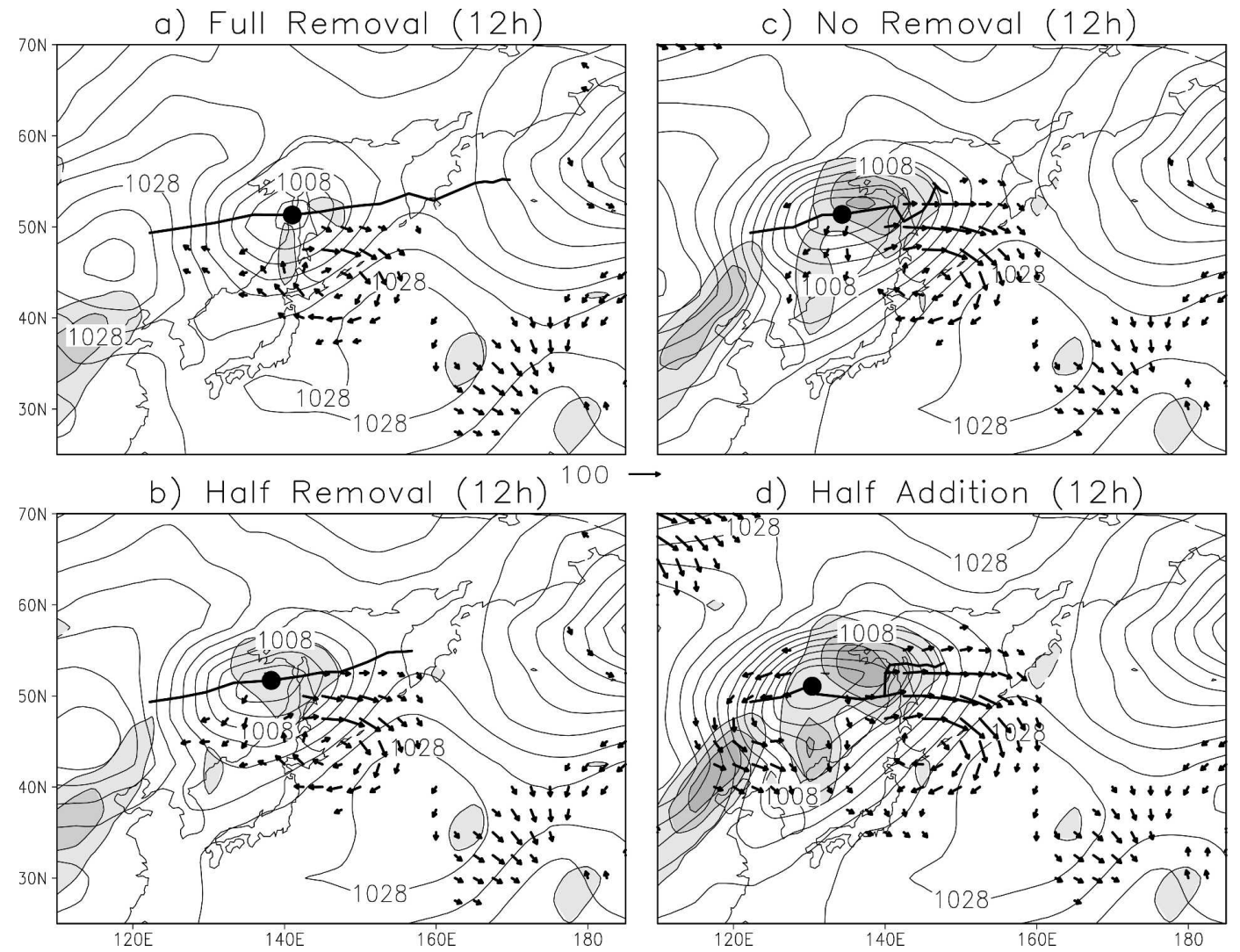

FIG. 6. Contributions to the generation of eddy kinetic energy at 1200 UTC 8 Mar 1977 (12 h). Shown are the (a) full removal, (b) half removal, (c) no removal (control), and (d) half addition simulations. Vertical integrals of baroclinic conversion are smoothed with a nine-point filter and shaded (at $25 \mathrm{~W} \mathrm{~m}^{-2}$ intervals). The ageostrophic geopotential flux is shown (except vectors less than $20 \mathrm{MW} \mathrm{m}^{-1}$, with a reference vector in the middle), along with sea level pressure (thin contours, 4-hPa intervals) and the tracks of the western North Pacific cyclone.

simulations. The corresponding energy centers of the half addition simulation and the ageostrophic geopotential fluxes between them are clearly the strongest among the four simulations (Fig. 7h). It follows that within a few days, the evolution of eddy kinetic energy across the North Pacific depends strongly on the presence of the upstream ridge and trough couplet at the initial time.

The impact of the upstream modifications is also apparent in the sea level pressure of the eastern cyclones when they reach maximum intensity on 11 March (Fig. 8). In terms of relative differences in horizontal length scale, following Nielsen and Dole (1992), the distance to the nearest col in the full removal simulation is only about two-thirds that of the control simulation. A complementary measure of cyclone size is the distance to the perimeter of a contiguous region of positive relative vorticity (Sinclair 1997; Simmonds 2000). The boldface contours of Fig. 8 represent such a measure and confirm an impressive reduction in size of the eastern cyclone in the full removal simulation. The stronger (control and half addition) cyclones are also associated with a more meridional track, as is characteristic of observed events (Sanders 1986).

All four simulated cyclones remain too intense near the coast of Alaska (cf. Fig. 3d), so we refer only to relative changes in their circulation and central pressure (Fig. 9). Circulation is defined here to be the areaweighted integral of positive relative vorticity (i.e., within the boldface contours shown in Fig. 8). We note that circulation is sensitive to a specification of this integration domain. When the eastern cyclones are mature at 1200 UTC 11 March, the intensity of the full removal cyclone appears to be reduced by about $25 \%$ relative to the control cyclone.

The central pressure traces of the four simulated cyclones (Fig. 9b) are quite comparable to that of the NCEP manual analysis, particularly in terms of minimum values. A 12-h delay in the simulated time of minimum central pressure corresponds to the delay in 
a) 12 UTC 8 March Full Removal (12h)

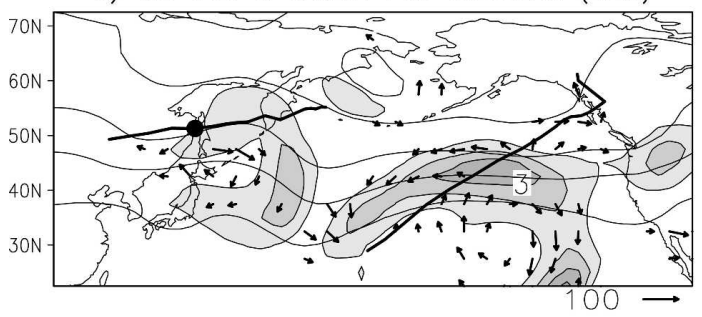

b) 00 UTC 10 March Full Removal (48h)

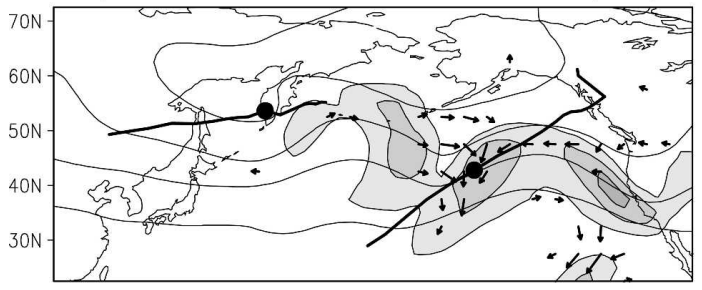

c) 12 UTC 11 March Full Removal (84h)

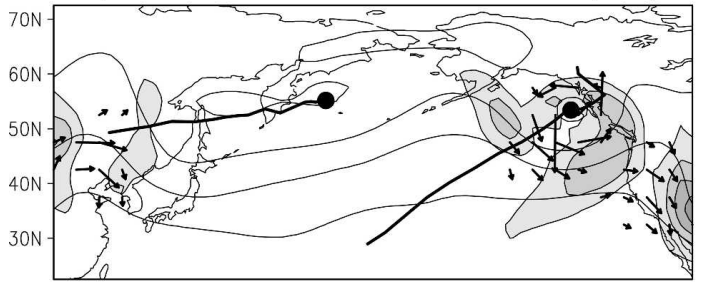

d) 12 UTC 11 March Half Removal (84h)

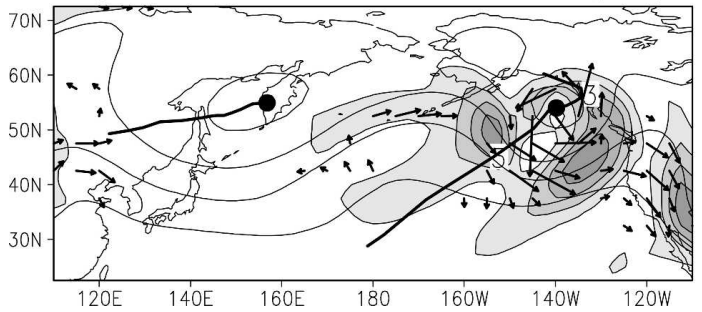

e) 12 UTC 8 March No Removal (12h)

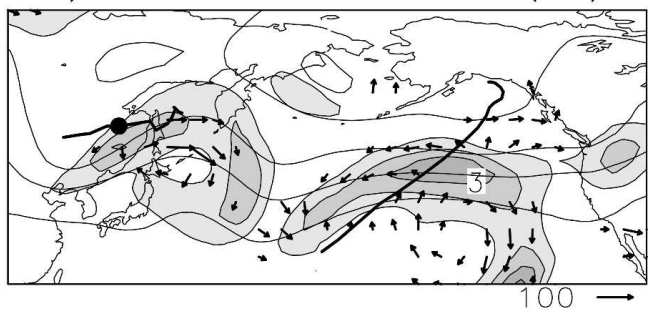

f) 00 UTC 10 March No Removal (48h)

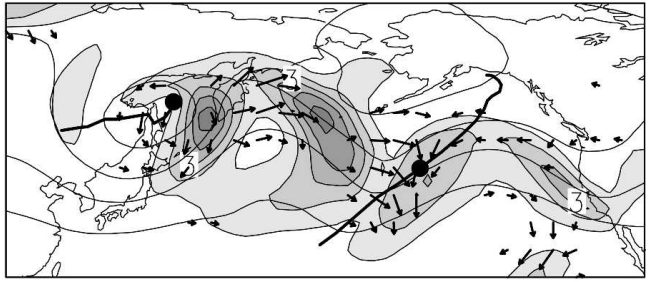

g) 12 UTC 11 March No Removal (84h)

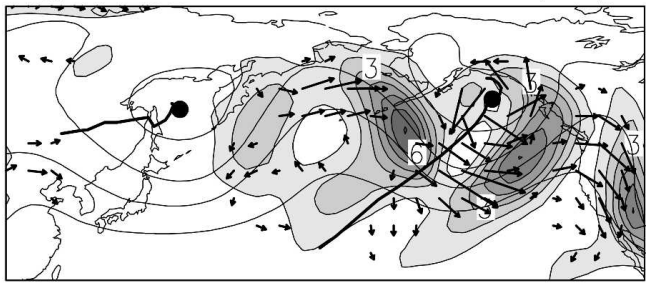

h) 12 UTC 11 March Half Addition (84h)

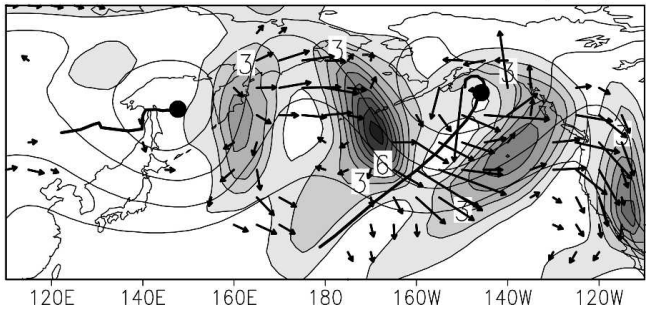

FIG. 7. Evolution of eddy kinetic energy in the (top half) full removal and no removal simulations and (bottom half) a comparison for all four simulations: vertical integrals of eddy kinetic energy and ageostrophic geopotential flux for the (a)-(c) full removal, (d) half removal, (e)-(g) no removal (control), and (h) half addition simulations. These are shown at (a), (e) 1200 UTC 8 Mar, (b), (f) 0000 UTC 10 Mar, and otherwise at 1200 UTC 11 Mar 1977. The contour interval is $1 \mathrm{MJ} \mathrm{m}^{-2}$ for eddy kinetic energy (shaded) and every other flux vector is shown, except those less than $20 \mathrm{MW} \mathrm{m}^{-1}$, with a reference vector above. The $500-\mathrm{hPa}$ height is thinly contoured at 30 -dam intervals.

the track of the eastern cyclone (recall Fig. 3) and may be partly attributable to the absence of a divergent flow in the initial conditions. The simulated eastern cyclones develop contemporaneously. This is consistent with the eastern troughs moving downstream past these cyclones at the same time (not shown) and ultimately contributing to their decay (Martin and Marsili 2002). (In other words, the upstream perturbations do not appear to strongly impact the phase speed of the eastern trough.) Notable differences in surface central pressure are found after 1200 UTC 9 March ( $36 \mathrm{~h}$ into the simulation). The difference between the full and control simulations at maximum intensity is just over $10 \mathrm{hPa}$. With all else unchanged, we can thus attribute about a quarter of the intensity of the eastern cyclone to the presence of a trough and ridge over Siberia 3 days earlier.

\section{Discussion}

It is instructive to place our results in the context of other studies that address cause and effect in cyclone 

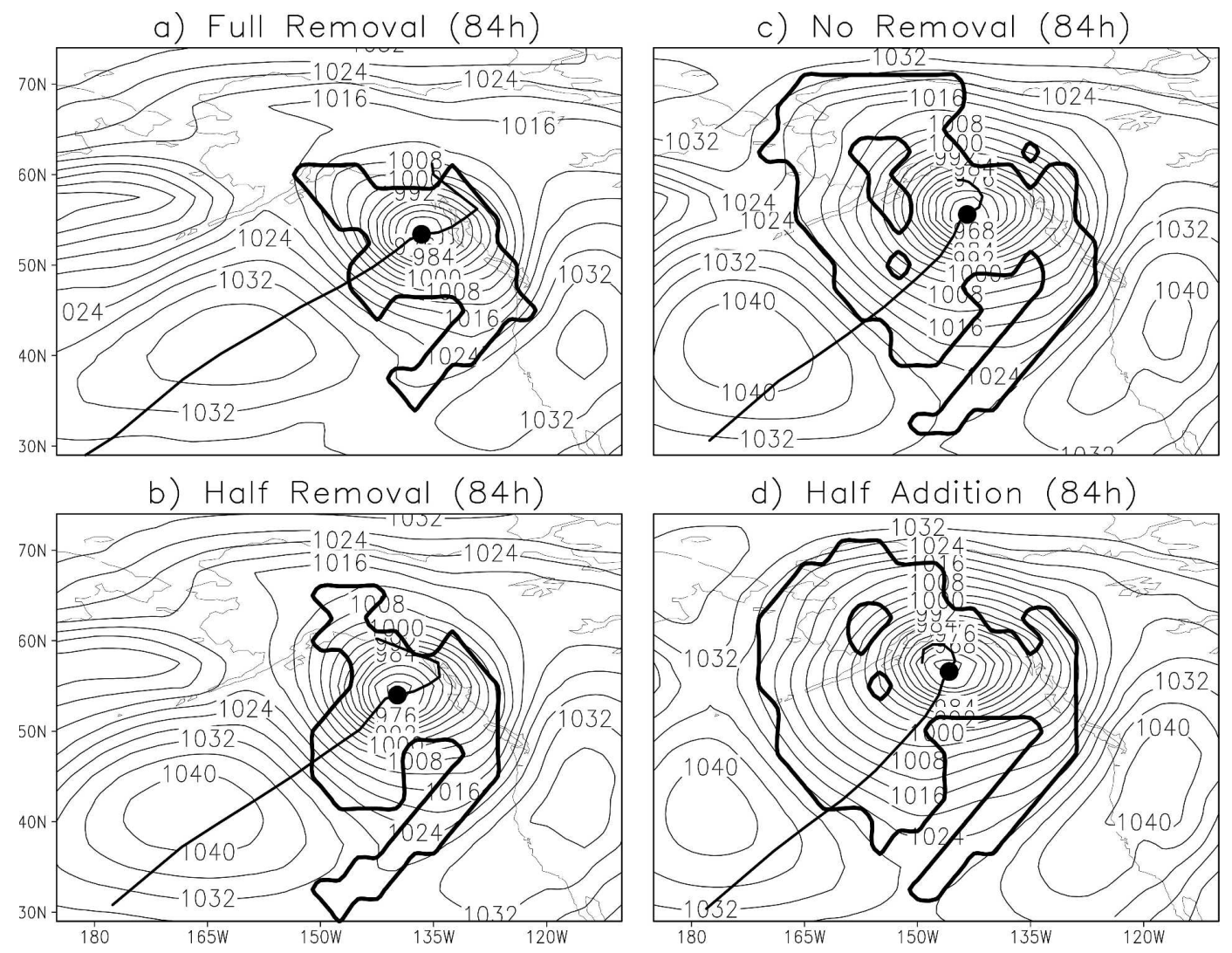

FIG. 8. Sea level pressure at 1200 UTC 11 Mar 1977 (84 h) for the (a) full removal, (b) half removal, (c) no removal (control), and (d) half addition simulations. The contour interval is $4 \mathrm{hPa}$. Also shown are the regions of positive relative vorticity used to calculate circulation at this time (see text). Thick lines with a dot are the tracks of the eastern surface cyclone.

development. We have found that the western and eastern troughs are connected by the propagation of eddy energy between them. This connection is made more explicit in Part II (see appendix), where a comparison of initial conditions in terms of wave activity (Takaya and Nakamura 2001) reveals our perturbations over Siberia to be a direct modification of the group of waves that subsequently defines the eastern cyclone. This direct connection to the eastern trough can also be demonstrated here by following the trajectories of air parcels whose PV is modified at 0000 UTC 8 March (cf. Fig. 4). The subsequent positions of these trajectories in the full removal simulation are shown at 0000 UTC 11 March in Fig. 10. Modified air parcels advance downstream such that those initially over Siberia are not only entrained into the eastern trough, but are located across the North Pacific Ocean.

The focus of this study is on perturbations to dynamical structures upstream, but an interesting question is what role physical processes play. For instance, the trajectories shown in Fig. 10 suggest that a direct impact on the eastern cyclone may occur even in the absence of diabatic and frictional processes within the western cyclone. A viable alternative to our perturbations of the primary circulation of the western cyclone is to modify its secondary circulation (Keyser and Uccellini 1987). In other words, the initial PV structure could be left intact and the cumulative role of moisture could be examined instead (e.g., latent heat release could be turned off). Based on the precipitation produced by the western cyclone (section 2), moist processes may not be as important as in the cyclones examined by, for example, Cammas et al. (1994) and Davis et al. (1996). However, a good fraction of the impact that we have attributed to the growth of the western cyclone in this study might be accounted for using this approach. This may also help to explain why downstream baroclinic development toward strong eastern North Pacific cyclones tends to be fed by baroclinic conversion in western cyclones (DGS). To facilitate an interpretation, moist processes could be perturbed in the western cyclone, but not in the eastern cyclone. 

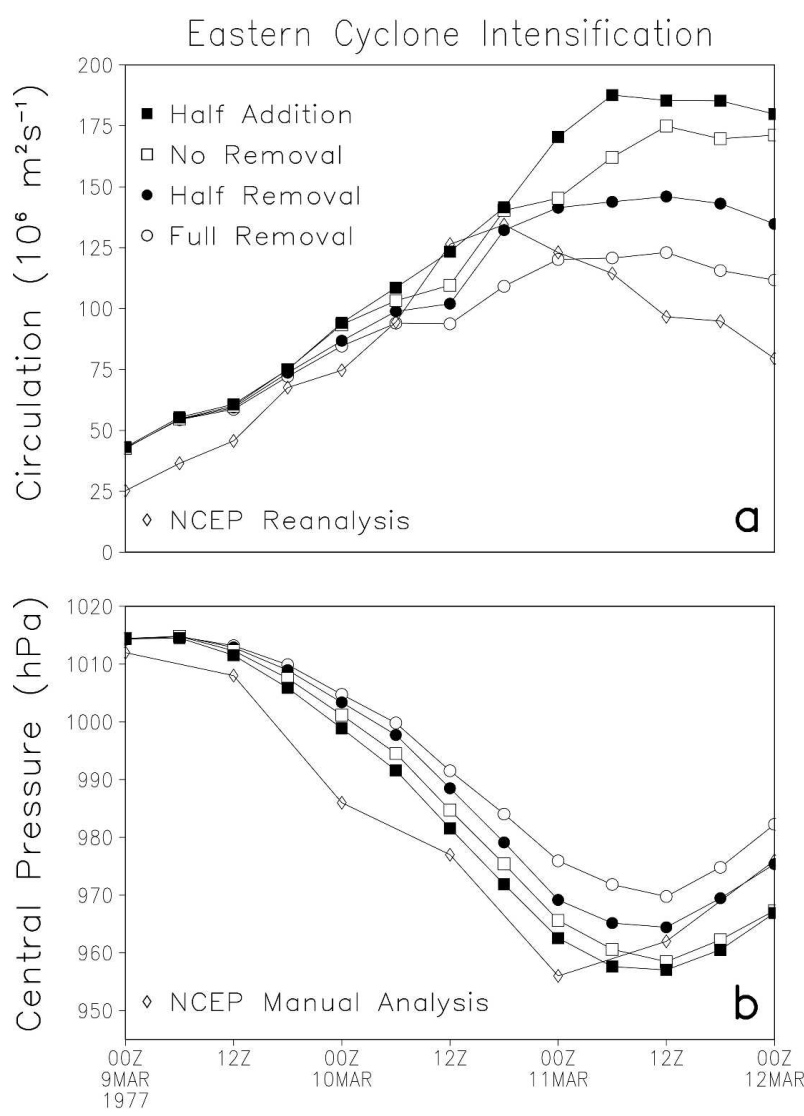

FIG. 9. Intensification of the simulated eastern North Pacific cyclone in terms of (a) surface relative circulation (in $10^{6} \mathrm{~m}^{2} \mathrm{~s}^{-1}$ ) and (b) central pressure (in $\mathrm{hPa}$ ). Values are shown at 6-h intervals for the half addition (closed square), no removal (open square), half removal (closed dot), and full removal (open dot) simulations. Also included is the circulation based on the NCEP reanalysis (above; diamond) and the central pressure based on the NCEP manual analyses (below, at 12-h intervals; diamond).

Perturbations employed in this study have been limited to regions upstream and at upper levels, but the role of many other initial structures that likely affect the eastern cyclone have not been addressed. Two features of interest are the western surface cyclone and the ridge downstream of the eastern cyclone (Figs. 3a and $3 \mathrm{f}$, respectively). If boundary potential temperature anomalies associated with the western surface cyclone are removed from the full removal initial conditions, there is a further reduction in the intensity of the eastern cyclone. This perturbation was not examined here because an unrealistically strong anticyclone dominates the upstream initial conditions, but it suggests that some of the development of the eastern cyclone can also be attributed in part to the western surface cyclone. (By contrast, when the western surface cyclone is modified and the Siberian wave at upper levels is not, a western cyclone nevertheless redevelops and down- stream baroclinic development follows.) If the amplitude of the ridge downstream of the eastern trough is reduced (mostly at upper levels), this seems to allow the eastern surface cyclone to spin up more easily. The corresponding eddy kinetic energy evolution is also enhanced, particularly in the eastern North Pacific region (not shown).

There are perhaps an infinite variety of ways in which to perturb the initial conditions. A more systematic approach is to quantify the sensitivity of the eastern cyclone directly. Such an approach is discussed, for example, by Hoskins et al. (2000), Gilmour et al. (2001), and Coutinho et al. (2004). In this context, it seems relevant that the evolution of 8-13 March 1977 appears to be relatively predictable (section 3 ) and that downstream energy propagation depends on the presence of the upstream ridge and trough couplet (section 5). One may thus ask whether the specific perturbations used here are required in order to significantly impact the eastern cyclone. Another consideration is that the eastern cyclone appears to respond almost linearly (or at least monotonically) to the upstream perturbations (Fig. 9). This may be examined in light of the proposition by Gilmour et al. (2001) that the atmospheric flow is unlikely to evolve linearly after more than a day. (It can be shown using their relative nonlinearity index that the error in assuming a linear evolution indeed exceeds $50 \%$ of the perturbations in $500-\mathrm{hPa}$ height within one day, but we recall that the amplitude of our half addition and half removal perturbations is also quite large.) A proper quantification of the sensitivity of the eastern cyclone is beyond our present scope. In terms of the propagation of eddy energy and wave activity, we return to the issue of nonlinearity in Part II.

\section{Conclusions}

The development of two extratropical cyclones that occur over different parts of the North Pacific Ocean during 8-13 March 1977 have been examined here. A western cyclone develops first, in association with a trough initially over Siberia, and is characterized by relatively light precipitation and surface winds. A few days later, an eastern trough and its associated surface cyclone intensify strongly. Following Keyser and Uccellini (1987), numerical simulations have been employed to quantify the dynamical impact on the eastern cyclone of variations in its upstream initial conditions. A control simulation over 5 days encompasses the full intensity of the western cyclone as well as the growth and decay of the eastern cyclone. Both cyclones verify well against surface observations and objective analyses. The S1 scores (Teweles and Wobus 1954) over the North Pacific are below 40 for the first 3 days, which 


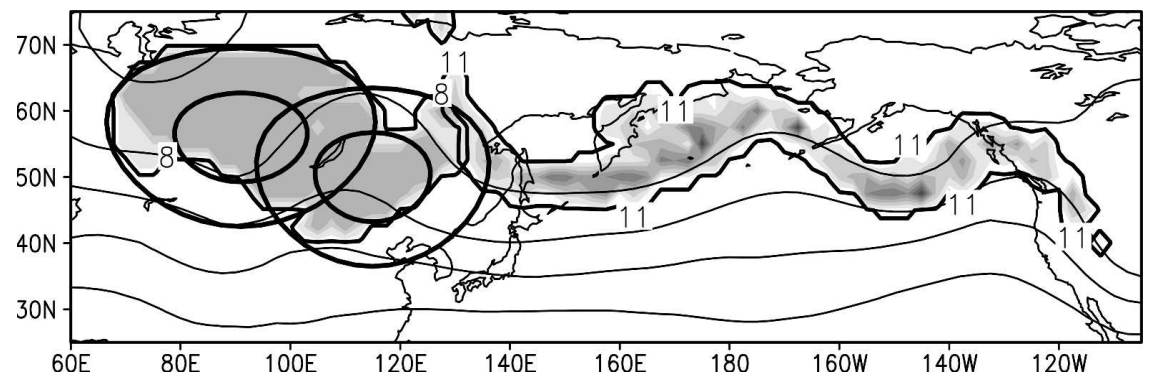

FIG. 10. Positions of 9000 trajectories starting from where PV is modified at 0000 UTC 8 Mar and ending at 0000 UTC 11 Mar 1977. Trajectories follow the three simulated wind components and are calculated using forward differences with a 30-min time step. (Wind components at 6-h intervals are linearly interpolated.) The two contours (8 and 11 Mar) delineate the regions containing trajectories (darker shading corresponds to higher density). Only trajectory positions at $250 \mathrm{hPa}$ are shown, along with 250-hPa height at $0000 \mathrm{UTC} 11 \mathrm{Mar}$ (thin contours at 30-dam intervals). The two pairs of concentric ovals are taken from Fig. 2.

suggests that this particular evolution may have been reasonably predictable.

Similar diagnoses of this event (DGS; Part II) indicate that eddy energy growth and radiation downstream is fed by baroclinic conversion near the western cyclone. Owing to a presumed forcing for ascent above the western cyclone (Petterssen and Smebye 1971), the western trough is deemed most likely to promote this energy growth and radiation. Both the western trough and a ridge farther upstream are modified in the initial conditions. Modification is performed using static PV inversion (DE91). This yields balanced initial conditions over a large part of the model domain, but with perturbations in the mass and wind fields being localized in the upstream regions. Four simulations have been considered, in which the eddy PV of the western ridge and trough are either removed to some degree or augmented.

A comparison of the resulting simulations revealed an estimated reduction of about a quarter in relative circulation or minimum central pressure associated with the full removal of the western trough and its upstream ridge. Some confirmation that this reduction is owing to the absence of downstream baroclinic development (Orlanski and Sheldon 1995) is found in the eddy energy evolution, which depicts a western energy center that fails to develop and subsequently disperse energy downstream. Finally, air parcel trajectories in the full removal simulation were examined to more fully apprehend the direct impact of upstream perturbations on the eastern cyclone. Supplementary experiments were also described, but it would be of interest to quantify the broader sensitivities of the eastern cyclone. This seems especially relevant given that the role of downstream baroclinic development remains largely unquantified on a case-by-case basis.
Acknowledgments. Comments on this study and on Part II by three anonymous reviewers helped to strengthen our presentation, and these are gratefully acknowledged. This research has been sponsored by the Natural Sciences and Engineering Research Council, Environment Canada, and the Canadian Foundation for Climate and Atmospheric Sciences. Dr. C. Davis is thanked for making available his potential vorticity inversion code, which we were stimulated to apply in discussion with Dr. R. McTaggart-Cowan. The ICOADS observations and the MM5 model were obtained from the National Center of Atmospheric Research, and gridded analyses were obtained through the Climate Diagnostics Center, both at Boulder, Colorado. Data visualization was facilitated by the GrADS software obtained from the Institute of Global Environment and Society at Calverton, Maryland.

\section{APPENDIX}

\section{Static Potential Vorticity Inversion over a Large Domain}

Experiments with static PV inversion are described here to indicate that the balanced mass and wind fields that are obtained can be sensitive to the initial calculation of PV. This appears to be particularly relevant when a large domain, such as the semicircular domain of Fig. 2, is employed. The numerical scheme used in this study is specified below, and although it does not concern static inversion directly, it is convenient to first describe the inversion method of DE91. A balance between the geopotential $\Phi$ and the streamfunction $\Psi$ is given by the nonlinear balance equation (Charney 1955) 


$$
\begin{aligned}
\nabla_{\pi}^{2} \Phi= & \nabla_{\pi} \cdot\left(f \nabla_{\pi} \Psi\right)+\frac{2}{a^{4} \cos ^{2} \varphi} \\
& \times\left(\frac{\partial^{2} \Psi}{\partial \lambda^{2}} \frac{\partial^{2} \Psi}{\partial \varphi^{2}}-\frac{\partial^{2} \Psi}{\partial \lambda \partial \varphi} \frac{\partial^{2} \Psi}{\partial \lambda \partial \varphi}\right)
\end{aligned}
$$

Here, $f$ is the Coriolis parameter, $a$ is the mean radius of the earth, $\lambda$ is longitude, and $\varphi$ is latitude. The operators $\nabla_{\pi}^{2}$ and $\nabla_{\pi}$ are the two-dimensional Laplacian and gradient operators, respectively, and the Exner function $\pi=C_{p}\left[p / p_{o}\right]^{\kappa}$ serves as the vertical coordinate $\left(C_{p}\right.$ is the specific heat capacity, $p$ is pressure, $p_{o}$ is reference pressure, and $\kappa$ is the gas constant to specific heat ratio).

To close the system describing balanced $\Psi$ and $\Phi$, a second equation and boundary conditions are needed. The second equation comes from an approximation of PV expressed in terms of $\Psi$ and $\Phi$ (DE91), which we refer to as the balanced PV

$$
\begin{aligned}
\mathrm{BPV}= & \frac{g \kappa \pi}{p}\left[\left(f+\nabla_{\pi}^{2} \Psi\right) \frac{\partial^{2} \Phi}{\partial \pi^{2}}-\frac{1}{a^{2} \cos ^{2} \varphi} \frac{\partial^{2} \Psi}{\partial \lambda \partial \pi} \frac{\partial^{2} \Phi}{\partial \lambda \partial \pi}\right. \\
& \left.-\frac{1}{a^{2}} \frac{\partial^{2} \Psi}{\partial \varphi \partial \pi} \frac{\partial^{2} \Phi}{\partial \varphi \partial \pi}\right],
\end{aligned}
$$

where $g$ is the constant of gravity. The relevant approximation here is that the nondivergent winds $\left(\mathbf{V}_{\Psi}=\hat{\mathbf{k}} \times\right.$ $\left.\nabla_{\pi} \Psi\right)$, rather than full winds, are employed in the last two terms on the rhs of (A2). Hence, PV and BPV are equivalent to a good approximation. The assumption that $\mathrm{PV} \approx \mathrm{BPV}$ yields (A1) and (A2), in terms of the two unknowns, $\Psi$ and $\Phi$. Boundary conditions are the observed $\Psi$ and $\Phi$ at lateral boundaries and their vertical gradients at the lower and upper boundaries, with the latter being equivalent to potential temperature.

As a check on our solution of balanced $\Psi$ and $\Phi$, we have used these to recompute PV (or equivalently BPV) and compare it with the initial PV calculated from the unbalanced fields. The assumption that $\mathrm{PV} \approx$ BPV implies that the two should be identical, in principle, although in practice they may be slightly different. This exercise reveals that the solution of balanced $\Psi$ and $\Phi$ at the center of a large inversion domain is sensitive to the numerical scheme used to calculate PV initially.

We have experimented with different discretizations and find that the PV formulation, which is as similar as possible to that used by the inversion algorithm to compute $\mathrm{BPV}$, is preferable. Hence,

$$
\begin{aligned}
\mathrm{PV}= & \frac{g \kappa \pi}{p}\left[\left(f+\nabla_{\pi}^{2} \Psi\right) \frac{\partial^{2} \Phi}{\partial \pi^{2}}-\frac{1}{a \cos \varphi} \frac{\partial V}{\partial \pi} \frac{\partial^{2} \Phi}{\partial \lambda \partial \pi}\right. \\
& \left.+\frac{1}{a} \frac{\partial U}{\partial \pi} \frac{\partial^{2} \Phi}{\partial \varphi \partial \pi}\right] .
\end{aligned}
$$

Note that this expression is identical to the hydrostatic form of Ertel PV in pressure and spherical coordinates (Hoskins et al. 1985), but requires higher-order differentiation. (It is sensitive to a representation of thermal structure by the geopotential and of small-scale features in the streamfunction. For instance, when PV is calculated using the geopotential instead of potential temperature, some of the thermal structure at upper levels in the subtropics is absent. At very high latitudes, the Laplacian of the streamfunction also appears to suffer relative to the same calculation using the wind field.)

Our rationale is that because the balanced output fields are a solution of (A2), the initial calculation of PV that is most consistent with the static inversion of DE91 is defined by (A3). We found that PV computed from the balanced output fields is most similar to the original PV when (A3) is used. The root-mean-square differences between the analyses and the balanced height (or streamfunction) are smaller as well. It is notable that DE91 suggest using lower-order differentiation in the calculation of PV. This is appropriate, however, because they also employ the time tendency of PV to calculate the balanced divergent wind field. Unless one is confident, for example, that the tendency of the streamfunction is well resolved, particularly at small length scales, it seems unlikely that (A3) is desirable for obtaining the balanced divergent winds.

\section{REFERENCES}

Cammas, J.-P., D. Keyser, G. Lackmann, and J. Molinari, 1994: Diabatic redistribution of potential vorticity accompanying the development of an outflow jet within a strong extratropical cyclone. Proc. Int. Symp. on Life Cycles of Extratropical Cyclones, Vol. II, Bergen, Norway, Aase Grafiske A/S, 403-409.

Chang, E. K. M., 1993: Downstream development of baroclinic waves as inferred from regression analysis. J. Atmos. Sci., 50, 2038-2053.

- , and I. Orlanski, 1993: On the dynamics of a storm track. $J$. Atmos. Sci., 50, 999-1015.

- and D. B. Yu, 1999: Characteristics of wave packets in the upper troposphere. Part I: Northern Hemisphere winter. $J$. Atmos. Sci., 56, 1708-1728.

Charney, J. G., 1955: The use of the primitive equations of motion in numerical prediction. Tellus, 7, 22-26.

Corfidi, S. F., and K. E. Comba, 1989: The meteorological operations division of the National Meteorological Center. Wea. Forecasting, 4, 343-366. 
Coutinho, M. M., B. J. Hoskins, and R. Buizza, 2004: The influence of physical processes on extratropical singular vectors. $J$. Atmos. Sci., 61, 195-209.

Daley, R., 1991: Atmospheric Data Analysis. Cambridge University Press, $457 \mathrm{pp}$.

Danielson, R. E., 2003: Environmental influences on cold-season cyclones over the North Pacific Ocean. Ph.D. thesis, McGill University, 224 pp. [Available from Richard E. Danielson, Dalhousie University, 1355 Oxford Street, Halifax, NS B3H 4J1, Canada.]

— - J. R. Gyakum, and D. Straub, 2004: Examples of downstream baroclinic development among 41 cold-season eastern North Pacific cyclones. Atmos.-Ocean, 42, 235-250.

,-- , and -2006 : A case study of downstream baroclinic development over the North Pacific Ocean. Part II: Diagnoses of eddy energy and wave activity. Mon. Wea. Rev., 134, $1549-1567$.

Davis, C. A., and K. A. Emanuel, 1991: Potential vorticity diagnostics of cyclogenesis. Mon. Wea. Rev., 119, 1929-1953.

_ E. D. Grell, and M. A. Shapiro, 1996: The balanced dynamical nature of a rapidly intensifying oceanic cyclone. Mon. Wea. Rev., 124, 3-26.

Gilmour, I., L. A. Smith, and R. Buizza, 2001: Linear regime duration: Is 24 hours a long time in synoptic weather forecasting? J. Atmos. Sci., 58, 3525-3539.

Grell, G. A., J. Dudhia, and D. R. Stauffer, 1994: A description of the fifth-generation Penn State/NCAR Mesoscale Model (MM5). NCAR Tech. Note NCAR/TN-398+STR, 117 pp.

Gyakum, J. R., and Coauthors, 1996: A regional model intercomparison using a case of explosive oceanic cyclogenesis. Wea. Forecasting, 11, 521-543.

Hoskins, B. J., M. E. McIntyre, and A. W. Robertson, 1985: On the use and significance of isentropic potential vorticity maps. Quart. J. Roy. Meteor. Soc., 111, 877-946.

— - R. Buizza, and J. Badger, 2000: The nature of singular vector growth and structure. Quart. J. Roy. Meteor. Soc., 126, 15651580.

Hsie, E.-Y., and R. A. Anthes, 1984: Simulations of frontogenesis in a moist atmosphere using alternative parameterizations of condensation and precipitation. J. Atmos. Sci., 41, 2701-2716.

Huo, Z., D.-L. Zhang, and J. R. Gyakum, 1999: Interaction of potential vorticity anomalies in extratropical cyclogenesis. Part II: Sensitivity to initial perturbations. Mon. Wea. Rev., 127, 2563-2575.

Kalnay, E., and Coauthors, 1996: The NCEP/NCAR 40-Year Reanalysis Project. Bull. Amer. Meteor. Soc., 77, 437-471.

Keyser, D., and L. W. Uccellini, 1987: Regional models: Emerging research tools for synoptic meteorologists. Bull. Amer. Meteor. Soc., 68, 306-320.

Kuo, H. L., 1974: Further studies of the parameterization of the influence of cumulus convection on large-scale flow. $J$. Atmos. Sci., 31, 1232-1240.

Kuo, Y.-H., and R. A. Anthes, 1984: Mesoscale budgets of heat and moisture in a convective system over the central United States. Mon. Wea. Rev., 112, 1482-1497.

- and R. J. Reed, 1988: Numerical simulation of an explo- sively deepening cyclone in the eastern Pacific. Mon. Wea. Rev., 116, 2081-2105.

Lee, S., and I. M. Held, 1993: Baroclinic wave packets in models and observations. J. Atmos. Sci., 50, 1413-1428.

Martin, J. E., and N. Marsili, 2002: Surface cyclolysis in the North Pacific Ocean. Part II: Piecewise potential vorticity diagnosis of a rapid cyclolysis event. Mon. Wea. Rev., 130, 1264-1281.

McTaggart-Cowan, R., J. R. Gyakum, and M. K. Yau, 2001: Sensitivity testing of extratropical transitions using potential vorticity inversions to modify initial conditions: Hurricane Earl case study. Mon. Wea. Rev., 129, 1617-1636.

Nielsen, J. W., and R. M. Dole, 1992: A survey of extratropical cyclone characteristics during GALE. Mon. Wea. Rev., 120, $1156-1167$.

Orlanski, I., and J. Katzfey, 1991: The life cycle of a cyclone wave in the Southern Hemisphere. Part I: Eddy energy budget. $J$. Atmos. Sci., 48, 1972-1998.

_, and E. K. M. Chang, 1993: Ageostrophic geopotential fluxes in downstream and upstream development of baroclinic waves. J. Atmos. Sci., 50, 212-225.

—, and J. P. Sheldon, 1993: A case of downstream baroclinic development over western North America. Mon. Wea. Rev., 121, 2929-2950.

_ and J. P. Sheldon, 1995: Stages in the energetics of baroclinic systems. Tellus, 47A, 605-628.

Petterssen, S., and S. J. Smebye, 1971: On the development of extratropical cyclones. Quart. J. Roy. Meteor. Soc., 97, 457482.

Sanders, F., 1986: Explosive cyclogenesis in the west-central North Atlantic Ocean, 1981-84. Part I: Composite structure and mean behavior. Mon. Wea. Rev., 114, 1781-1794.

Simmonds, I., 2000: Size changes over the life of sea level cyclones in the NCEP reanalysis. Mon. Wea. Rev., 128, 4118-4125.

Simmons, A. J., and B. J. Hoskins, 1979: The downstream and upstream development of unstable baroclinic waves. $J$. Atmos. Sci., 36, 1239-1254.

Sinclair, M. R., 1997: Objective identification of cyclones and their circulation intensity, and climatology. Wea. Forecasting, 12, 595-612.

Takaya, K., and H. Nakamura, 2001: A formulation of a phaseindependent wave-activity flux for stationary and migratory quasigeostrophic eddies on a zonally varying basic flow. $J$. Atmos. Sci., 58, 608-627.

Teweles, S., and H. B. Wobus, 1954: Verification of prognostic charts. Bull. Amer. Meteor. Soc., 35, 455-463.

Wolf, B. J., and D. R. Johnson, 1995a: The mesoscale forcing of a midlatitude upper-tropospheric jet streak by a simulated convective system. Part I: Mass circulation and ageostrophic processes. Mon. Wea. Rev., 123, 1059-1087.

_ and _ 1995b: The mesoscale forcing of a midlatitude upper-tropospheric jet streak by a simulated convective system. Part II: Kinetic energy and resolution analysis. Mon. Wea. Rev., 123, 1088-1111.

Woodruff, S. D., H. F. Diaz, J. D. Elms, and S. J. Worley, 1998: COADS release 2 data and metadata enhancements for improvements of marine surface flux fields. Phys. Chem. Earth, 23, 517-526. 